\title{
Preparação para a Aposentadoria: Implantação e Avaliação do Programa Viva Mais!
}

\author{
Preparing for Retirement: Implementation and Evaluation \\ of the Live More! Program
}

\author{
Sheila Giardini Murta*, Samia Abreu, Cristineide Leandro França, Marina Pedralho, \\ Juliana Seidl, Nadielle de Paula Moura Lira, Rochelly Karen Moreira Carvalhedo, \\ Ana Carolina da Conceição \& Isolda de Araújo Gunther \\ Universidade de Brasília, Brasília, Distrito Federal, Brasil
}

\begin{abstract}
Resumo
O objetivo deste artigo é descrever o processo de implementação e avaliação do Viva Mais! - o programa de preparação para aposentadoria (PPA) de uma Universidade pública brasileira. Para tal, utilizou-se um modelo lógico baseado em insumos, produtos, resultados, pressupostos e fatores externos. Treze participantes inscritos foram divididos em dois grupos que receberam 24 horas de intervenção informativa e vivencial durante oito semanas. Os temas basearam-se nos preditores do envelhecimento bem-sucedido. Utilizou-se a análise de conteúdo para interpretar as respostas dos participantes nas entrevistas de avaliação de resultados. Os dados demonstraram que o principal objetivo do programa - promover o bem-estar, a saúde e a qualidade de vida dos trabalhadores da Universidade - foi alcançado.

Palavras-chave: Pré-aposentadoria, aposentadoria, envelhecimento, intervenção, avaliação

Abstract

The aim of this paper is to describe the process of establishment and evaluation of Live More! the retirement planning program of a Brazilian public university. A logic model based on inputs, outputs, results, assumptions and external factors was used. Thirteen employees were divided into two groups receiving 24 hours of informative and experiential intervention during eight weeks. The topics' selection was based on the predictors of successful aging. Content analysis was adopted to interpret the participants' answers in the evaluation interviews. Results demonstrated that the main goal of the program - to promote workers' well-being, health and quality of life - was achieved.

Keywords: Pre-retirement, retirement, aging, intervention, evaluation.
\end{abstract}

Transições no âmbito da formação profissional e do trabalho são esperadas desde a juventude até o envelhecimento. Incluem, por exemplo, concluir o ensino médio ou superior e ingressar no primeiro emprego; mudar de um trabalho para outro em um mesmo ramo ou em ramo distinto; deixar o trabalho por diversas razões, como mudança geográfica, desemprego ou aposentadoria e retornar às atividades laborais após um período de afastamento (Fouad \& Bynner, 2008). Todas estas transições podem requerer adaptação e resultar em algum grau de estresse. Por isto, constituem-se em momentos oportunos para a implantação de ações de prevenção ou promoção de saúde mental (Muñoz, Mrazek, \& Haggerty, 1996).

Dentre estas transições relativas ao trabalho, a aposentadoria tem se configurado como uma das mais discutidas

\footnotetext{
*Endereço para correspondência: Universidade de Brasília, Campus Darcy Ribeiro, Departamento de Psicologia Clínica, Instituto de Psicologia, 70.910-900, ICC/Sul, Brasília-DF, Brasil. E-mail: giardini@unb.br
}

por diferentes segmentos da sociedade, incluindo pesquisadores das áreas de trabalho, saúde e envelhecimento, profissionais de gestão de pessoas, e formuladores de políticas públicas em saúde do trabalhador e/ou envelhecimento. Neste contexto, um dos focos investigados é o impacto da aposentadoria sobre a saúde mental dos aposentados e os fatores que facilitam ou dificultam o ajustamento a esta transição de vida.

$\mathrm{O}$ ajustamento à aposentadoria é um fenômeno heterogêneo, com aumento na satisfação com a vida para uns, diminuição para outros e até mesmo estabilidade na satisfação com a vida entre aposentados (García \& Ruiz, 2000). Revisão sobre estudos internacionais que avaliam adaptação à aposentadoria (Wang, Henkens, \& Van Solinge, 2011) identificou evidências de que perdas em saúde física, possuir filhos dependentes financeiramente, perder o parceiro durante a transição, aposentar-se mais cedo do que o esperado e aposentar-se por problemas de saúde são condições que afetam negativamente a adaptação à aposentadoria. Por outro lado, ter saúde física e mental, 
aposentar-se por decisão própria, usufruir de bom status financeiro, engajar-se em lazer e trabalho formal ou voluntário, ter planejado a aposentadoria, aposentar-se para fazer outras atividades, ter boa relação conjugal e estar insatisfeito com o trabalho ou desempregado antes da aposentadoria são condições favoráveis ao ajustamento após a aposentadoria.

Acesso a recursos sociais, financeiros e informativos é outra condição diretamente associada a melhor ajustamento (Wang et al., 2011). Embora o número de estudos com amostras de brasileiros aposentados seja pequeno, existem evidências de uma estreita relação entre recursos e ajustamento também entre aposentados dos setores privado (Duarte \& Melo-Silva, 2009) e público (Oliveira, Torres, \& Albuquerque, 2009) no Brasil.

No setor privado, foram encontrados relatos de experiências de angústia e ansiedade no período pré-aposentadoria e frustração e decepção com os proventos pós-aposentadoria, indicando que a escassez de recursos financeiros e informativos representa uma fonte de sofrimento para um grupo de 30 trabalhadores que participaram de um estudo longitudinal (Duarte \& Melo-Silva, 2009). Em um estudo com 110 homens aposentados de cargos públicos, os preditores de bem estar pós-aposentadoria estão relacionados ao planejamento da aposentadoria, à satisfação com a saúde, às relações sociais e à mobilidade, resultante de ter carro próprio e morar em bairro bem localizado (Oliveira et al., 2009).

Nesta mesma linha, outros estudos indicam que o acesso a recursos é a principal condição facilitadora da qualidade de vida na aposentadoria e no envelhecimento tardio, sejam os recursos associados às finanças e ao planejamento partilhado com o cônjuge (Noone, Stephens, \& Alpass, 2010), à saúde e expectativas positivas para com a aposentadoria (Fouquereau, Fernandez, Fonseca, Paul, \& Uotinen, 2005), ao lazer, à escolaridade e à manutenção de vínculos na comunidade (Argimon \& Stein, 2005).

Estes estudos oferecem muitas orientações para o desenho dos objetivos e conteúdo dos programas de preparação para a aposentadoria. Os programas deveriam maximizar o controle do trabalhador sobre o processo de planejamento e decisão para aposentar-se (Feldman \& Beehr, 2011; Vaus, Wells, Kendig, \& Quine, 2007) e, sobretudo, facilitar a identificação, a criação e o uso de recursos promotores de qualidade de vida na transição para a aposentadoria.

Conforme proposto por Adams e Rau (2011), os programas de preparação para a aposentadoria devem auxiliar os participantes a encontrar respostas para as perguntas: "O que vou fazer? Como vou sustentar isto? Com quem vou partilhar isto? Onde vou viver." Neste sentido, publicações internacionais (Adams \& Rau, 2011; Lee \& Law, 2004) e nacionais (Costa \& Soares, 2009; França \& Carneiro, 2009; França \& Soares, 2009; Soares, Costa, Rosa, \& Oliveira, 2007) têm sinalizado a necessidade de abrangência do conteúdo destes programas de preparação para a aposentadoria (PPAs). Estes devem cobrir áreas como a ocupação, as finanças, a moradia, a saúde e as relações sociais e afetivas, além de aspectos legais da aposentadoria.

Em PPAs descritos na literatura nacional (Muniz, 1997; Murta, Caixeta, Souza, \& Ribeiro, 2008; Soares et al., 2007) e em publicações didáticas que ensinam ou discutem como implementá-los (Costa \& Soares, 2009; França, 2002; França \& Soares, 2009; Zanelli, Silva, \& Soares, 2010) tais temas são usualmente abordados em módulos informativos e vivenciais, contando frequentemente com facilitadores internos (membros da equipe) e externos (convidados para temas específicos). É comum serem dirigidos a trabalhadores que estejam mais próximos da aposentadoria, faltando entre dois a cinco anos para se aposentar (Costa \& Soares, 2009), ainda que possam também incluir pessoas recém-ingressas na empresa, numa perspectiva preventiva e de educação ao longo da vida (França \& Soares, 2009).

Para além do planejamento do conteúdo e formato das intervenções, os pesquisadores com experiência na implementação de PPAs ressaltam também os cuidados com a sua avaliação (França, 2002; Murta et al., 2008; Soares et al., 2007; Zanelli et al., 2010). Diversas etapas integram a avaliação dos PPAs: (a) avaliações prévias ao programa para levantamento de necessidades e sensibilização de gestores, (b) avaliação de processo feita no decorrer do programa para monitoramento dos exitos e dificuldades em sua condução e (c) avaliação de resultados para identificação das mudanças produzidas pela intervenção sobre os participantes. Esta última avaliação pode ser longitudinal e incluir o acompanhamento dos participantes até três anos após a sua aposentadoria (França \& Carneiro, 2009).

Mesmo com um substancial progresso em estudos e publicações nacionais quanto às diretrizes para a implementação de PPAs, são poucas as empresas brasileiras que oferecem estes programas como parte de suas ações para promoção de saúde do trabalhador (Costa \& Soares, 2009; França \& Carneiro, 2009; França \& Soares, 2009), consideradas as realidades dos setores privado e público. Neste último contexto, apenas recentemente o Ministério do Planejamento, Orçamento e Gestão, por meio da Secretaria de Recursos Humanos, criou a Portaria SRH no. 1.261 de 05 de maio de 2010, que objetiva instituir a Política de Atenção à Saúde do Servidor - PASS (Portaria $\mathrm{n}^{\circ}$ 1.261, 2010). Esta política prevê a implementação de PPAs, além de outras ações de promoção e assistência à saúde do servidor público federal. Tal política pública se alinha a outras, um pouco mais antigas, como a Política Nacional do Idoso (Lei $\left.n^{\circ} 8.842,1994\right)$ e o Estatuto do Idoso (Lei $\left.\mathrm{n}^{\circ} 10.741,2003\right)$ que também preveem a oferta de PPAs como ações de promoção de saúde no envelhecimento.

Essas políticas públicas, se implementadas integralmente, podem facilitar o envelhecer com dignidade. Isto se torna particularmente relevante na contemporaneidade, quando a expectativa de vida se tornou maior do que no passado (Green, 2010) e é esperado que um número crescente de pessoas viva pelo menos um quarto da vida na condição de aposentados (Lee \& Law, 2004). Dada 
Murta, S. G., Abreu, S., França, C. L., Pedralho, M., Seidl, J., Lira, N. P. M., Carvalhedo, R. K. M., Conceição, A. C., \& Gunther, I. A. (2014). Preparação para a Aposentadoria: Implantação e Avaliação do Programa Viva Mais!.

a relevância social do tema, a Universidade de Brasília vem se engajando na criação de um programa de preparo para a aposentadoria para seus servidores. A descrição do processo de implantação e avaliação deste programa, chamado Viva Mais!, é o objetivo deste artigo.

\section{Contexto Organizacional}

A referida instituição de ensino superior possui atualmente cerca de 400 profissionais que já podem se aposentar, mas continuam trabalhando. Cerca de $40 \%$ do quadro de 3926 servidores possuíam critérios para se aposentar até 2012, o que corresponde a mais de 1500 pessoas.

O planejamento da implantação do programa vem ocorrendo desde meados de 2006, quando uma equipe foi formada para fazer um levantamento de ações semelhantes já realizadas no serviço público federal Nesse período foram realizados projetos, palestras e seminários sobre a temática. Em meados de 2009, a equipe foi consolidada e no início de 2010 as ações de implantação tiveram início.

\section{Objetivos do Programa Viva Mais!}

O principal objetivo do Programa Viva Mais! é promover o bem-estar, a saúde e a qualidade de vida dos trabalhadores da Universidade de Brasília, mobilizando-os para o enfrentamento das vulnerabilidades decorrentes da transição para a aposentadoria e possibilitando-os experienciar uma aposentadoria bem-sucedida.

Deste modo, os objetivos finais do programa são diminuir o surgimento de dificuldades emocionais nos anos que antecedem e sucedem a aposentadoria (tais como, quadros de estresse e depressão) e melhorar a qualidade de vida, definida como a presença de independência funcional, engajamento em atividades sócio-ocupacionais, vivência de vínculos afetivos e percepção de satisfação com a vida.

\section{Fundamentos do Programa}

Uma das estratégias utilizadas para a implantação do programa foi a tomada de decisão quanto a seus fundamentos. Para tanto, foi desenvolvido um modelo lógico do Viva Mais!, a fim de melhorar a consistência global e a gerencialidade do programa. Os principais elementos do modelo lógico são: (a) os insumos, que incluem os recursos humanos, organizacionais, financeiros e políticos; (b) as atividades, que constituem os processos, que combinados com os insumos, produzem bens e serviços; (c) os produtos, que são os bens ou serviços resultantes do processo de produção de uma atividade; (d) os resultados, que correspondem às mudanças e benefícios associados à implementação das atividades do programa e (e) os fatores de contexto, que são as variáveis-chave, fora do controle da gestão do programa, que podem criar condições favoráveis ou desfavoráveis ao desempenho do programa (Cassiolato \& Gueresi, 2010).
A partir destes conceitos, o Viva Mais! foi organizado de acordo com a Figura 1.

As atividades indicadas no modelo lógico serão descritas detalhadamente, visto que são etapas fundamentais para alcançar os objetivos do programa.

\section{Fases de Implantação do Programa}

\section{Avaliação de Necessidades}

A avaliação de necessidades teve início com a revisão da literatura sobre programas de preparação para a aposentadoria e estudos sobre indicadores de envelhecimento bem-sucedido. Esta etapa precedeu o programa e foi realizada com trabalhadores aposentados da instituição, com a finalidade de levantar subsídios para o planejamento do programa, de tal forma que este atendesse às demandas do público-alvo. Os instrumentos para avaliação de necessidades foram: (a) roteiro de entrevista semiestruturada para aposentados, composto por cinco questões abertas e (b) roteiro para grupo focal com servidores aposentados, que também continha cinco questões abertas. As questões da entrevistas e grupo focal abordavam as características do processo de transição para aposentadoria, as vivências positivas e negativas, as estratégias de enfrentamento adotadas após a aposentadoria e sugestões para trabalhadores que estejam em preparo para a aposentadoria.

As informações foram transcritas e submetidas à técnica qualitativa de Análise de Conteúdo do tipo Temática e Estrutural (Bardin, 1977). Verificou-se que $75 \%$ dos aposentados tiveram uma experiência negativa com o processo de aposentadoria. Esses participantes indicaram "sentimentos de incapacidade para outras atividades" e "desejo de manutenção das redes sociais" como principais fatores anteriores à aposentadoria, e "falta de planejamento" e "dúvidas em relação ao processo" como fatores recorrentes durante o processo. Em relação ao período pós-aposentadoria, citaram comportamentos como " $m a$ nutenção de rotinas relacionadas ao trabalho", "aumento das tarefas domésticas", "desejo de voltar a trabalhar" e "manifestação de transtornos psicológicos". Os outros $25 \%$, que relataram sentimentos positivos, indicaram um engajamento na preparação da aposentadoria com "negociação de datas com superiores" e "planejamentos das atividades". Foram identificadas estratégias de enfrentamento, como "comprar imóvel ou investir no imóvel atual", "oferecer serviços particulares" e "participar de grupos el ou atividades da comunidade". Foram sugeridos "cursos de capacitação", "orientação para uma nova carreira", "prevenção ao alcoolismo" e "orientação jurídica".

Os resultados sugeriram um suporte incipiente da instituição na preparação de seus trabalhadores para esta fase, evidenciando a urgência da implantação do programa. Em consequência, foram discutidas as implicações dos resultados para o conteúdo do grupo psicoeducativo com a proposta de intervenções relacionadas ao autocuidado à saúde, educação financeira, redes sociais e orientação profissional. 


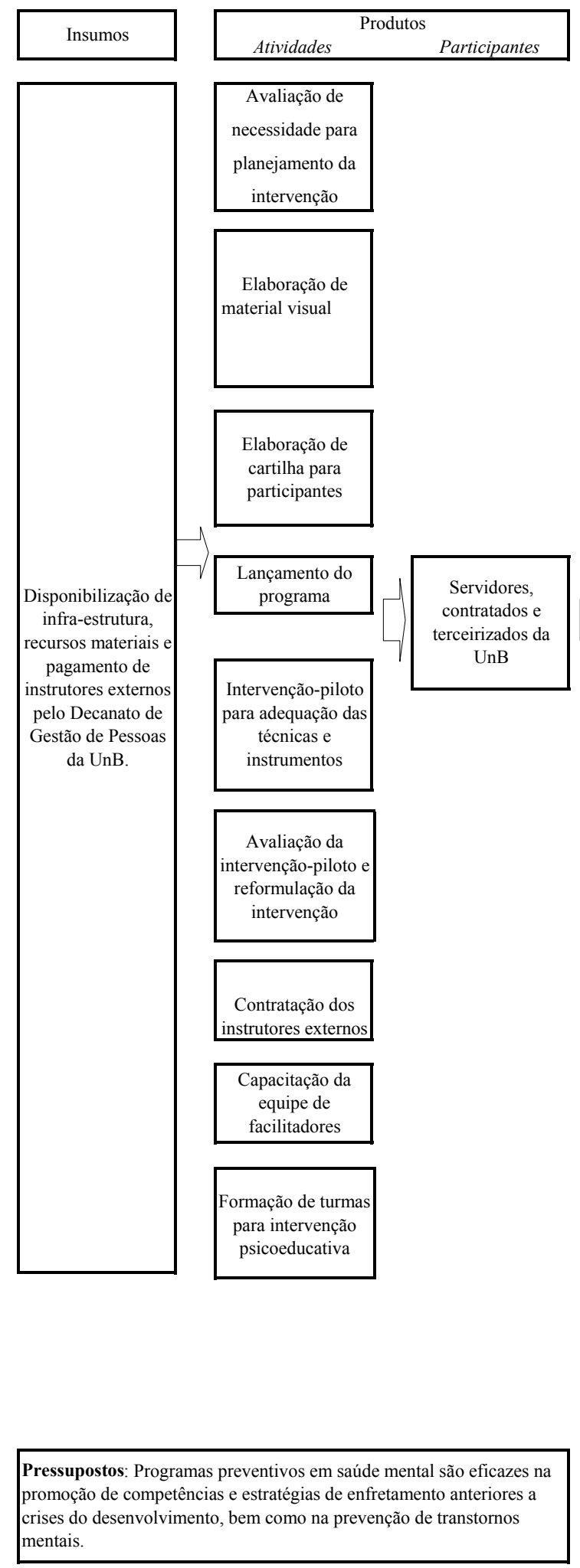

Figura 1. Modelo Lógico do Programa Viva Mais!

\section{Criação de Identidade Visual}

A escolha do nome "Viva Mais!" para o programa se deu a partir das sugestões da equipe organizadora e de alguns trabalhadores da instituição, por meio de votação, permitindo assim a participação da comunidade universitária.

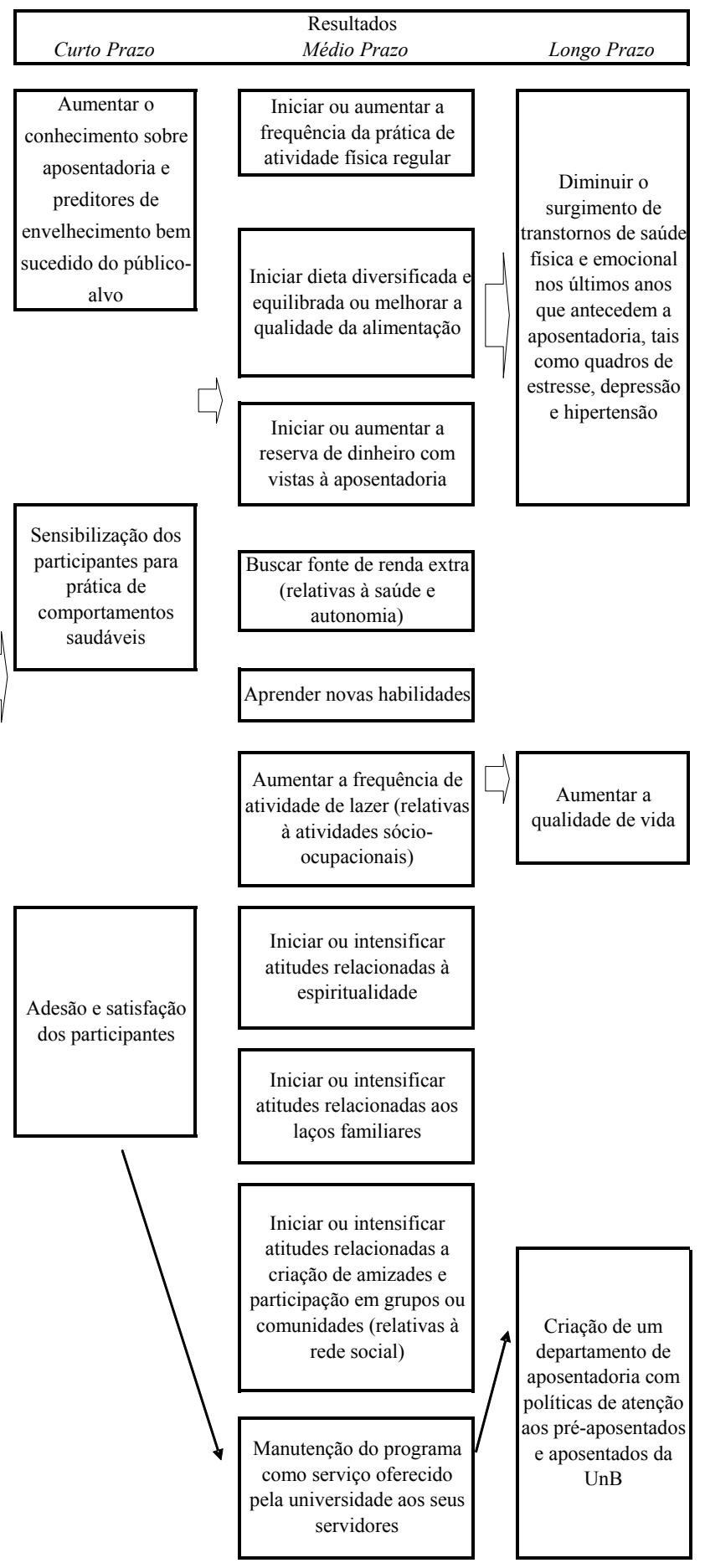

Fatores Externos: Alterações no programa de previdência do governo federal, mudanças de gestão na instituição e mudanças na rotina dos participantes (como mortes, separação conjugal entre outros)

\section{Criação de Guia para Participantes}

Simultaneamente à criação da identidade visual, a equipe de implantação do programa desenvolveu um Guia para os Participantes (Murta et al., 2010). O Guia é dividido em 10 capítulos, com os seguintes temas: critérios 
Murta, S. G., Abreu, S., França, C. L., Pedralho, M., Seidl, J., Lira, N. P. M., Carvalhedo, R. K. M., Conceição, A. C., \& Gunther, I. A. (2014). Preparação para a Aposentadoria: Implantação e Avaliação do Programa Viva Mais!.

para se aposentar e tipos de aposentadoria existentes; procedimentos para requerer a aposentadoria; enfrentamento às transições de vida; preditores de qualidade de vida na aposentadoria; saúde; manejo de finanças; rede de apoio social; ocupação, lazer e processo de mudança. Além disto, foram incluídos ao final da cartilha três capítulos como anexos sobre os (a) recursos da universidade e da cidade na qual está localizada, (b) sugestões de livros, filmes e sites e (c) direitos do idoso.

A escolha dos temas de cada capítulo decorreu das demandas levantadas pelos participantes durante a fase de avaliação de necessidades, bem como da revisão de literatura sobre preditores de adaptação à aposentadoria (Oliveira et al., 2009; Wang et al., 2011) e elementos constituintes de programas de preparação (Costa \& Soares, 2009; França \& Carneiro, 2009; França \& Soares, 2009; Muniz, 1997; Soares et al., 2007). A inserção de recursos informativos e comunitários ao longo do texto foi uma resposta à relevância de instrumentalizar os participantes para a mudança e promover seu empoderamento (Adams \& Rau, 2011; Fouad \& Bynner, 2008; Wang et al., 2011).

\section{Sensibilização e Divulgação}

Antes do lançamento do programa, foram realizadas visitas à Associação de Servidores Aposentados e Sindicato de Servidores da Universidade, para a apresentação dos objetivos do programa e o estabelecimento de parcerias. Além disso, informações sobre o Viva Mais! foram disponibilizadas no site institucional e convites para participação no programa foram entregues individualmente nos centros de custos e enviados por e-mail para os servidores efetivos, contratados e terceirizados. Um e-mail específico foi destinado às chefias e gerências dos centros de custos, com a solicitação da liberação dos servidores interessados em participar do programa.

Essa é uma etapa que demandou cuidado e sensibilidade por parte da equipe, já que consistia na primeira vez que os participantes teriam contato com o novo programa e havia a possibilidade, já identificada na avaliação de necessidades, dos trabalhadores interpretarem o programa como uma maneira de segregar as pessoas que estavam próximas da aposentadoria ou de acelerar tal processo. Com a finalidade de evitar ou minimizar possíveis interpretações negativas, a divulgação do programa incluiu como público-alvo todos os trabalhadores da universidade, independente do vínculo (servidores efetivos, contratados e terceirizados) e da faixa etária (não apenas para participantes próximos da aposentadoria mas para qualquer trabalhador interessado no tema). A inclusão de todos os trabalhadores é coerente com a abordagem de prevenção universal (Muñoz et al., 1996) e de educação ao longo da vida (França \& Soares, 2009).

\section{Lançamento}

O lançamento contou com a presença de autoridades ligadas à administração superior da instituição e membros da comunidade universitária. Neste momento, foram distribuídos exemplares do Guia para Participantes. Duas semanas após o lançamento, iniciou-se o período de inscrição dos interessados em participar da intervenção-piloto.

\section{Formação dos Grupos e Conteúdo da Intervenção}

A inscrição dos interessados em participar da intervenção foi realizada por telefone durante duas semanas. Com uma quantidade suficiente de inscritos (16), foram formados dois grupos, sendo que 13 servidores concluíram a intervenção. Os participantes eram em sua maioria do sexo feminino (67\%), entre 50 e 60 anos (92\%), acrescidos por um participante com mais de 60 anos e outro participante com menos de 30 anos, que havia se aposentado por invalidez. A escolaridade dos participantes dividiu-se em ensino superior (42\%), ensino médio (42\%) e fundamental (16\%), atuando como servidores administrativos (93\%) e docentes (7\%). Para 59\% dos participantes faltavam dois anos ou menos para se aposentarem, $25 \%$ deles possuiam tempo suficiente para pedir a aposentadoria, um participante com a previsão de três anos e um participante já aposentado por invalidez.

O programa contou com intervenções estruturadas em oito módulos informativos e vivenciais em um formato psicoeducativo, com duração de três horas semanais, totalizando 24 horas de programa para cada grupo de participantes. Os módulos informativos, ministrados por instrutores externos (médico geriatra, educador físico, servidor da universidade especialista em legislação em aposentadoria e economista), foram executados em forma de palestras, com a exposição de informações e a interação entre o expositor e os participantes para esclarecimento de dúvidas e comentários livres. Os módulos vivenciais, conduzidos por psicólogos da equipe, em dupla ou trio, foram realizados por meio de atividades interativas para promoção de auto-observação, sensibilização, tomada de decisão e enfrentamento, além de prevenção à recaída. Os temas abordados foram: preditores de envelhecimento bem sucedido; processo de mudança e resiliência; critérios para a aposentadoria e legislação; família e rede social; saúde física; autonomia financeira; novos talentos e pós-carreira; e projeto de vida. Em geral, os 90 minutos iniciais da sessão eram dedicados aos módulos vivenciais, enquanto os 90 minutos finais eram utilizados para os módulos informativos. Nos módulos vivenciais, atividades grupais foram utilizadas, baseadas no Modelo Transteórico de Mudança (Prochaska \& DiClemente, 1983; Prochaska, DiClemente, \& Norcross, 1992), de modo a encorajar processos favorecedores da mudança, incluindo a auto-observação, a tomada de consciência, a tomada de decisão, o estabelecimento de planos de ação, a prevenção de recaídas e a troca de apoio social entre os participantes.

\section{Avaliação de Processo}

Esta avaliação tinha por objetivo monitorar a qualidade de cada sessão da intervenção. Os facilitadores dos grupos 
respondiam ao final de cada encontro um Protocolo de Avaliação de Processo, que compreendia dados coletados a partir da observação direta de comportamentos emitidos pelos participantes nas interações entre eles e entre eles e os facilitadores durante as sessões.

Os critérios do protocolo de avaliação de processo utilizados foram a dose recebida (verbalizações de prática ou uso das ferramentas disponibilizadas na intervenção, verificadas ao início da sessão), satisfação (atitudes favoráveis ou desfavoráveis ao programa, avaliadas ao final da sessão) e integridade ou fidelidade (correspondência entre os procedimentos e objetivos abordados e os previstos para a sessão do dia; Steckler \& Linnan, 2002). O protocolo incluía também metas intermediárias (comportamentos do grupo indicadores de adesão e envolvimento nas sessões ocorridas em qualquer momento da sessão), desempenho dos facilitadores (habilidades sociais dos facilitadores na relação com os participantes durante toda a sessão) e sentimentos dos facilitadores (sentimentos vivenciados pelos facilitadores no decorrer da sessão).

Outras fontes de dados foram as descrições das tarefas de casa. Ao fim de cada encontro, as facilitadoras sugeriam uma tarefa ou os participantes escolhiam algo para fazer durante a semana, relacionado ao último encontro ou aos encontros anteriores. Os participantes recebiam um pequeno papel que continha a imagem de um pé, simbolizando uma caminhada, e uma pergunta sobre o que o participante havia colocado em prática do programa, com espaço para o preenchimento. A prática foi definida para os participantes como "planejar, desejar ou fazer", incluindo aspectos cognitivos, motivacionais e comportamentais, coerentemente com o Modelo Transteórico de Mudança (Prochaska \& DiClemente, 1983; Prochaska et al., 1992).

Os dados foram analisados pela técnica de Análise de Conteúdo do tipo Temática e Estrutural (Bardin, 1977). Inicialmente, o conteúdo do protocolo de avaliação de processo e do formulário de tarefa de casa passou pela análise flutuante, que consiste em uma avaliação geral do material a ser avaliado, seguida pela análise vertical, por meio do agrupamento de conteúdos semelhantes em categorias. Esta fase contou com dois codificadores e um juiz que era acionado em caso de divergências. Como última etapa da análise, foi realizada a comparação e a horizontalização, ou seja, a junção e soma de frequência das categorias classificadas para a visualização geral dos dados.

Foram encontrados 85 relatos divididos em seis categorias de áreas de investimento descritas pelos participantes no decorrer da intervenção, a saber: ocupação (27,05\%), saúde $(27,05 \%)$, laços afetivos e sociais $(20 \%)$, aposentadoria $(9,42 \%)$, finanças $(8,23 \%)$ e autoconhecimento $(7,05 \%)$. Os relatos de práticas dos participantes e as frequências, relacionados à categoria aposentadoria, foram: a tomada de consciência em relação à aposentadoria (3) e o planejamento de questões legais relativas à mesma (5). Na categoria finanças, os participantes indicaram a realização de atividades com fins lucrativos (3) e o cuidado com as finanças (4), como a quitação de dívidas bancárias. Quanto à categoria laços afetivos e sociais, foi mencionado o cultivo de amizades (7), laços familiares (8) e a relação com o parceiro (2). Além disso, investimento na atividade profissional (6), cumprimento de obrigações (6), lazer (5) e responsabilidades com bens materiais (6) foram temas que apareceram na categoria ocupação. Por fim, na categoria autoconhecimento, foram apontados os seguintes temas: lidar com mudanças (4) e reflexão sobre os próprios comportamentos (2).

A partir da análise inicial dos dados, constatou-se que o conteúdo assimilado e colocado em prática pelos participantes (dose recebida) foi coerente com o que foi oferecido durante a intervenção (dose fornecida), visto que os passos dos participantes foram dados em direção às áreas de investimentos fomentados e discutidos nos encontros do programa. As mudanças relatadas pelos participantes como decorrentes do programa se configuram como recursos promotores de saúde, podendo facilitar a adaptação à aposentadoria, de acordo com dados de estudos na área (Argimon \& Stein, 2005; Fouquereau et al., 2005; Noone et al., 2010; Wang et al., 2011) e com outras experiências nacionais de programas de preparação para a aposentadoria (França, 2002; Murta et al., 2008; Soares et al., 2007; Zanelli et al., 2010).

\section{Avaliação dos Resultados}

Dois meses após o término da intervenção, os participantes foram entrevistados individualmente por membros da equipe e questionados sobre os ganhos decorrentes de sua participação no Viva Mais!, o que menos gostaram e o que mais gostaram no programa. No mês seguinte, os participantes foram convidados para um pós-encontro, quando construíram com sucatas e materiais gráficos o que haviam aprendido durante os encontros e o que mantinham em sua vida. As falas foram transcritas e, para tratamento, utilizou-se a técnica de Análise Temática e Estrutural de Bardin (1977). As respostas dos entrevistados à primeira pergunta foram organizadas em dez categorias, apresentadas na Tabela 1, com as respectivas definições, frequências e relatos ilustrativos.

Considerando a avaliação sobre o que menos gostaram no programa, foram discriminadas cinco categorias, das quais se destacam as seguintes: duração (4) "Achei muito curto, poderia haver mais encontros"; conteúdo (3) "Considero que o programa deveria ter palestras sobre atividades fisicas, independência [capacidade de viajar sozinha], dar mais opções para observar a aposentadoria como algo positivo"; ampliação da divulgação e captação dos participantes (2) "Levar o conhecimento às pessoas que estão próximas a se aposentar..."; assiduidade dos participantes (1) "Só achei que poderia ser mais cobrada a assiduidade das pessoas" e, por fim, ausência de críticas (1) "Não tenho nada a reclamar, tinha meus planos em minha mente e os retomei com o grupo". 
Murta, S. G., Abreu, S., França, C. L., Pedralho, M., Seidl, J., Lira, N. P. M., Carvalhedo, R. K. M., Conceição, A. C., \& Gunther, I. A. (2014). Preparação para a Aposentadoria: Implantação e Avaliação do Programa Viva Mais!.

Tabela 1

Categorias de Análise da Pergunta "O Que Você Levou do Programa Viva Mais!?”

\begin{tabular}{|c|c|c|c|}
\hline Categoria & Definição da categoria & Frequência & Fala dos participantes \\
\hline $\begin{array}{l}\text { Relacionamentos } \\
\text { com amigos }\end{array}$ & $\begin{array}{l}\text { Reconhecimento } \\
\text { da importância da rede } \\
\text { social e integração grupal }\end{array}$ & 5 & $\begin{array}{l}\text { "A parte de relacionamento foi o que mais aprendi } \\
\text { com o PPA, estar mais atento à forma como me } \\
\text { relaciono } \\
\text { com as pessoas" }\end{array}$ \\
\hline Finanças & $\begin{array}{l}\text { Planejamento das finanças } \\
\text { e controle sobre os gastos } \\
\text { pessoais e familiares }\end{array}$ & 4 & $\begin{array}{l}\text { "A palestra sobre finanças me ajudou a me } \\
\text { atentar mais e me controlar para comprar menos. } \\
\text { Consegui sair do cheque especial" }\end{array}$ \\
\hline Planejamento & $\begin{array}{l}\text { Conscientização e domínio } \\
\text { sobre sua vida na preparação } \\
\text { para a aposentadoria }\end{array}$ & 4 & $\begin{array}{l}\text { "Entendi que preciso ter planejamento para eu } \\
\text { me aposentar... Me proporcionou a reflexão e o } \\
\text { planejamento, vou ficar mais um ano aqui..." }\end{array}$ \\
\hline Saúde & $\begin{array}{l}\text { Cuidados e atenção } \\
\text { com a saúde }\end{array}$ & 3 & $\begin{array}{l}\text { "Também passei a me controlar e beber menos . } \\
\text { Melhorar a alimentação..." }\end{array}$ \\
\hline Estudos & $\begin{array}{l}\text { Conhecimento e } \\
\text { aprimoramento profissional }\end{array}$ & 2 & $\begin{array}{l}\text { "Estou fazendo curso de espanhol e pretendo fazer } \\
\text { o mestrado" }\end{array}$ \\
\hline Espiritualidade & $\begin{array}{l}\text { Aquisição de práticas } \\
\text { religiosas }\end{array}$ & 2 & $\begin{array}{l}\text { "Valeu para trabalhar a minha espiritualidade. } \\
\text { Toda quinta-feira eu vou à missa e eu não ia antes" }\end{array}$ \\
\hline Atividade física & $\begin{array}{l}\text { Iniciar ou manter o hábito de } \\
\text { realizar atividade física }\end{array}$ & 2 & $\begin{array}{l}\text { "Sempre ouvi do médico que eu deveria fazer } \\
\text { atividade fisica e só hoje eu percebo que eu tenho } \\
\text { que fazer" }\end{array}$ \\
\hline Família & $\begin{array}{l}\text { Fortalecimento dos vínculos } \\
\text { familiares }\end{array}$ & 2 & $\begin{array}{l}\text { "Já dei minha cota e quero ficar mais perto da } \\
\text { esposa ... Aprendi a falar com ela no momento } \\
\text { adequado e a colocar em prática a tolerância" }\end{array}$ \\
\hline Lazer & $\begin{array}{l}\text { Realização de práticas de } \\
\text { lazer }\end{array}$ & 1 & $\begin{array}{l}\text { "O lazer também está em mente, estamos } \\
\text { caminhando no parque e assumi a responsabilidade } \\
\text { de levar e buscar meus netos na escola" }\end{array}$ \\
\hline Segunda carreira & $\begin{array}{l}\text { Perspectivas para o futuro } \\
\text { por meio de uma segunda } \\
\text { carreira }\end{array}$ & 1 & $\begin{array}{l}\text { "Depois que me aposentar vou continuar } \\
\text { trabalhando, quero ser um representante externo..." }\end{array}$ \\
\hline
\end{tabular}

A constatação sobre o que mais gostaram no programa envolve os seguintes aspectos: técnicas utilizadas (4) "Gostei muito do desenho do corpo e do círculo das redes sociais"; trabalho em grupo (4) ". . . o trabalho em grupo é bom pra ver que todos têm seus problemas"; estrutura do programa (3) "Pra mim tudo foi muito bom porque a gente já fica com aquilo [conteúdo, forma de agir] na mente. Eu senti muita diferença depois do PPA"; aprendizado obtido por meio do programa (3) "Percebi a importância dos relacionamentos com amigos e pessoas que estão mais distantes"; participar da família (1) "Participar com a minha esposa ..." e receber feedback dos terapeutas (1) "Gostei de estar com os terapeutas. Gostei muito das terapeutas darem feedback para cada um de nós".

\section{Discussão}

Os fatores que facilitam ou dificultam o ajustamento antes e após a aposentadoria (Wang et al., 2011) foram aspectos abordados ao longo do programa, por meio do compartilhamento de informações entre o grupo, utilização de técnicas que despertassem estas descobertas e feedback constante das facilitadoras. Assim, os participantes puderam desenvolver e fortalecer as mudanças relatadas, como o controle dos gastos financeiros, os cuidados com a saúde, a valorização do lazer, a iniciação ou manutenção de atividade física, a alimentação saudável, o fortalecimento dos vínculos e a possibilidade de investir em uma nova carreira.

Esses resultados, percebidos como positivos, corroboram os estudos sobre a importância do acesso a recursos 
que facilitem a qualidade de vida na aposentadoria e no envelhecimento, sejam os recursos associados às finanças, ao planejamento partilhado com o cônjuge (Noone et al., 2010), à saúde e à expectativas positivas para com a aposentadoria (Fouquereau et al., 2005), ao lazer, à escolaridade e à manutenção de vínculos na comunidade (Argimon \& Stein, 2005).

Como apontado pela literatura (França, 2002; Murta et al., 2008; Soares et al., 2007; Zanelli et al., 2010) os cuidados com a avaliação do programa são importantes para que ele possa ser aprimorado continuamente e promova mudanças favoráveis à aposentadoria e ao envelhecimento bem-sucedido. Nessa perspectiva, foram cumpridas pelo programa Viva Mais! as diferentes etapas que integram a avaliação dos PPAs: avaliações prévias ao programa, para levantamento de necessidades e sensibilização de gestores; avaliação de processo, feita no decorrer do programa, para monitoramento dos êxitos e dificuldades em sua condução e avaliação de resultados, para identificação das mudanças produzidas pela intervenção sobre os participantes.

Os relatos dos participantes coletados no decorrer e ao final do programa indicam que a intervenção foi bem-sucedida no alcance de seus objetivos. Todos os entrevistados relataram ganhos após participarem do Viva Mais! e manifestaram essa satisfação por meio de forte vínculo com as facilitadoras, do conteúdo das falas no momento da avaliação e das expressões verbais e não-verbais de alívio e segurança dos colaboradores no último módulo onde todos manifestaram conhecer melhor o caminho que leva a uma aposentadoria bem-sucedida.

Algumas medidas podem ser tomadas para aprimoramento do programa. Em primeiro lugar, ações de sensibilização às chefias devem ser empreendidas (França \& Carneiro, 2009; Zanelli et al., 2010). Neste sentido, o programa deixaria de focar apenas em mudanças individuais e incluiria também mudanças organizacionais, mais abrangentes. Em segundo lugar, sugere-se o planejamento de ações para os servidores docentes. Considerando que a maior parte dos participantes eram servidores administrativos (93\%), torna-se relevante desenvolver meios para atrair docentes para o programa ou torná-lo mais adequado às demandas e limitações deste grupo de servidores. Em terceiro lugar, conforme proposto por França e Soares (2009), ações voltadas para os servidores recém-chegados à instituição seriam também pertinentes. No conjunto, esses ajustes aumentariam o alcance do programa e seus benefícios para a Instituição.

As sugestões dadas pelos participantes ao longo do programa e durante a avaliação de resultados forneceram subsídios importantes em termos de perspectivas futuras para as próximas intervenções do Viva Mais!. Observada a insatisfação relacionada à baixa carga horária, os temas para as turmas do próximo semestre já foram reorganizados em 12 módulos (ao invés de oito), incluindo: mitos e verdades sobre a aposentadoria no primeiro encontro; pós-carreira e empreendedorismo como tema do penúltimo encontro; desmembrando o tema rede social e família em dois encontros e saúde em três encontros - atividade física, alimentação saudável e sexualidade.

No que se refere ao aumento da divulgação, foram adotadas novas estratégias para mobilizar um número maior de possíveis interessados. Uma delas foi sugerir aos atuais participantes que comentassem com colegas de trabalho. Além disso, antes do início das inscrições, diferentes mídias locais (jornal e televisão) fizeram reportagens para promover o programa e e-mails foram enviados a todos os trabalhadores da instituição.

Por fim, acredita-se que para acompanhar cada participante ao longo do processo de entrada nesta nova fase da vida, seria recomendado o acompanhamento dos participantes por três anos após a aposentadoria, tal como proposto por França e Carneiro (2009). Este procedimento também permitiria verificar o impacto do programa na saúde após a aposentadoria e avaliar se as metas a médio e longo prazo definidas pelo modelo lógico foram alcançadas.

Tendo em vista que a oferta de programas de preparação para a aposentadoria é ainda pequena em organizações brasileiras (Costa \& Soares, 2009; França \& Soares, 2009), espera-se que a descrição deste estudo, em seus êxitos e limitações, possa colaborar para o avanço das pesquisas e serviços destinados a este público. Espera-se, sobretudo, que esta iniciativa se some a outras de modo a contribuir para a consolidação da Política de Atenção à Saúde do Servidor (Portaria $\left.\mathrm{n}^{\mathrm{o}} 1.261,2010\right)$ e para a difusão de programas preventivos na transição para a aposentadoria. Estes, se teoricamente embasados e criteriosamente avaliados, podem contribuir para que os trabalhadores em transição para a aposentadoria possam responder com menor sofrimento e mais otimismo às perguntas " $\mathrm{O}$ que vou fazer? Como vou sustentar isto? Com quem vou partilhar isto? Onde vou viver?" (Adams \& Rau, 2011) e possam, consequentemente, viver mais e melhor.

\section{Referências}

Adams, G. A., \& Rau, B. L. (2011). Putting off tomorrow to do what you want today: Planning for retirement. American Psychologist, 21, 1-13.

Argimon, I. I. L., \& Stein, L. M. (2005). Habilidades cognitivas em indivíduos muito idosos: Um estudo longitudinal. Cadernos de Saúde Pública, 21(1), 64-72.

Bardin, L. (1977). Análise de conteúdo. Lisboa, Portugal: Edições 70.

Cassiolato, M., \& Gueresi, S. (2010). Como elaborar Modelo Lógico: Roteiro para formular programas e organizar avaliação. Brasília, DF: Instituto de Pesquisa Econômica Aplicada.

Costa, A. B., \& Soares, D. H. P. (2009). Orientação psicológica para a aposentadoria. Revista Psicologia: Organizações e Trabalho, 9(2), 97-108.

Duarte, C. V., \& Melo-Silva, L. L. (2009). Expectativas diante da aposentadoria: Um estudo de acompanhamento em momento de transição. Revista Brasileira de Orientação Profissional, 10(1), 45-54. 
Murta, S. G., Abreu, S., França, C. L., Pedralho, M., Seidl, J., Lira, N. P. M., Carvalhedo, R. K. M., Conceição, A. C., \& Gunther, I. A. (2014). Preparação para a Aposentadoria: Implantação e Avaliação do Programa Viva Mais!.

Feldman, D. C., \& Beehr, T. A. (2011). A three-phase model of retirement decision making. American Psychologist, 66(3), 193-203.

Fouad, N. A., \& Bynner, J. (2008). Work transitions. American Psychologist, 63, 241-251.

Fouquereau, E., Fernandez, A., Fonseca, M. A., Paul, M. C., \& Uotinen, V. (2005). Perceptions of and satisfaction with retirement: A comparison of six European Union countries. Psychology and Aging, 20, 524-528.

França, L. H. (2002). Repensando a aposentadoria com qualidade: Um manual para facilitadores em programas de educação para a aposentadoria. Rio de Janeiro, RJ: Universidade Aberta da Terceira Idade, Universidade do Estado do Rio de Janeiro.

França, L. H., \& Carneiro, D. (2009). Programas de preparação para a aposentadoria: Um estudo com trabalhadores mais velhos em Resende (RJ). Revista Brasileira de Geriatria e Gerontologia, 12(3), 429-448.

França, L. H., \& Soares, D. (2009). Preparação para a aposentadoria como parte da educação ao longo da vida. Psicologia: Ciência e Profissão, 29, 738-751.

García, A. J. M., \& Ruiz, E. J. G. F. (2000). La preparación para la jubilación: revisión de los factores psicológicos y sociales que inciden en un mejor ajuste emocional al final del desempeño laboral. Anales de Psicología, 16(1), 87-99.

Green, L. (2010). You could live a long time: Are you ready? Toronto, Canada: Thomas Allen.

Lee, W. K. M., \& Law, K. W. K. (2004). Retirement planning and retirement satisfaction: The need for a national retirement program and policy in Hong Kong. The Journal of Applied Gerontoloy, 23, 212-233.

Lei $\mathrm{n}^{\circ} 10.741$, de $1^{\circ}$ de outubro de 2003. (2003, 3 out.). Dispõe sobre o Estatuto do Idoso e dá outras providências. Diário Oficial da União.

Lei n $^{\circ} 8.842$, de 4 de janeiro de 1994. (1994, 4 jan.). Dispõe sobre a Política Nacional do Idoso, cria o Conselho Nacional do Idoso e dá outras providências. Diário Oficial da República Federativa do Brasil.

Muniz, J. A. (1997). PPA: Programa de preparação para o Amanhã. Estudos de Psicologia (Natal), 2(1), 198-204.

Muñoz, R. F., Mrazek, P. J., \& Haggerty, R. J. (1996). Institute of Medicine Report on Prevention of Mental Disorders: Summary and commentary. American Psychologist, 51, 1116-1122.

Murta, S. G., Caixeta, T. D., Souza, K. L., \& Ribeiro, D. C. (2008). Avaliação de um programa de preparo para a aposentadoria e envelhecimento bem-sucedido. In S. G. Murta (Ed.), Grupos Psicoeducativos: Aplicações em Múltiplos Contextos (pp. 181-196). Goiânia, GO: Porã Cultural.

Murta, S. G., Oliveira, S. A., Siqueira, A. L. N., Carvalhedo, R. K. M., Gunther, I. A., Lira, N. P. M., ...Naves, M. (2010). Viva Mais! Programa de Preparação para a Aposentadoria: Guia para Participantes. Brasília, DF: Universidade de Brasília.

Noone, J. H., Stephens, C., \& Alpass, F. M. (2010). Do men and women still differ in their retirement planning? Testing a theoretical model of gendered pathways to retirement preparation. Research on Aging, 31, 295-317.

Oliveira, C., Torres, A. R. R., \& Albuquerque, E. S. (2009). Análise do bem estar psicossocial de aposentados de Goiânia. Psicologia em Estudo, 14, 749-757.

Portaria $\mathrm{n}^{\mathrm{o}} 1.261$, de 5 de maio de 2010. (2010). Institui os Princípios, Diretrizes e Ações em Saúde Mental que visam orientar os órgãos e entidades do Sistema de Pessoal Civil - SIPEC da Administração Pública Federal sobre a saúde mental dos servidores. Brasília, DF: Secretaria de Recursos Humanos, Ministério do Planejamento, Orçamento e Gestão.
Prochaska, J. O., \& DiClemente, C. C. (1983). Stages and processes of self-change of smoking: Toward an integrative model of change. Journal of Consulting and Clinical Psychology, 51, 390-395.

Prochaska, J. O., DiClemente, C. C., \& Norcross, J. C. (1992). In search of how people change. Aplications to addictive behaviors. Americam Psychologist, 47, 1102-1114.

Soares, D. H. P., Costa, A., Rosa, A. M., \& Oliveira, M. L. (2007). Aposenta-ação: Programa de preparação para a aposentadoria. Estudos Interdisciplinares sobre o Envelhecimento, 13, 123-134.

Steckler, A., \& Linnan, L. (2002). Process evaluation for public health interventions and research. An overview. In A. Steckler \& L. Linnan (Eds.), Process evaluation for public health interventions and research (pp. 1-21). San Francisco, CA: Jossey-Bass.

Vaus, D., Wells, Y., Kendig, H., \& Quine, S. (2007). Does gradual retirement have better outcomes than abrupt retirement? Results from an Australian panel study. Aging \& Society, 27, 667-682.

Wang, M., Henkens, K., \& Van Solinge, H. (2011). Retirement adjustment: A review of theoretical and empirical advancements. American Psychologist, 66(3), 204-213.

Zanelli, J. C., Silva, N., \& Soares, D. H. P. (2010). Orientação para aposentadoria nas organizações de trabalho: Construção de projetos para o pós-carreira. Porto Alegre, RS: Artmed. 